Вісник Харківського національного університету імені В.Н. Каразіна Серія "Математика, прикладна математика і механіка"

Том 93,2021 , c. $18-33$

УДК 517.962 .22
Visnyk of V.N.Karazin Kharkiv National University Ser. "Mathematics, Applied Mathematics and Mechanics"

Vol. 93, 2021, p. 18-33

DOI: $10.26565 / 2221-5646-2021-93-03$

\title{
Implicit linear difference equations over a non-Archimedean ring
}

\author{
A. B. Goncharuk \\ V. N. Karazin Kharkiv National university, \\ 4 Svobody sqr., Kharkiv, 61022, Ukraine \\ angoncharuk@ukr.net
}

The present article gives sufficient conditions for the existence and uniqueness of the solution of an implicit linear difference equation of an arbitrary order over a certain class of non-Archimedean rings, in particular a ring of formal power series. It is shown that this solution can be found using the Cramer rule. Some results on such equations over a ring of polynomials are also given.

Keywords: difference equations; non-Archimedean valuation; ring of polynomials.

Гончарук А. Б. Неявні лінійні різницеві рівняння над неархімедовими кільцями. У статті наводяться достатні умови для існування та єдиності розв'язку неявного лінійного різницевого рівняння будь-якого порядку над деяким класом неархімедових кілець, зокрема кільцем формальних степеневих рядів. Показано, що цей розв'язок можна знайти за допомогою правила Крамера. Також наведені деякі результати щодо таких рівнянь над кільцем поліномів.

Ключові слова: різницеве рівняння; неархімедове нормування; кільце поліномів.

Гончарук А. Б. Неявные линейные разностные уравнения над неархимедовыми кольцами. В статье приводятся достаточные условия существования и единственности решения неявного линейного разностного уравнения любого порядка над некоторым классом неархимедовых колец, в частности над кольцом формальных степенных рядов. Показано, что это решение может быть найдено с помощью правила Крамера. Приводятся также некоторые результаты, касающиеся таких уравнениях над кольцом многочленов.

Ключевые слова: разностные уравнения; неархимедово нормирование; кольцо многочленов.

2010 Mathematics Subject Classification: 12J25; 39A06.

\section{Introduction}

In the article [1] a simple interesting fact about recurrence equations is discovered: there is shown that the infinite implicit system of linear equations in variables $x_{0}, x_{1}, x_{2}, \ldots$

(C) A. B. Goncharuk, 2021 


$$
b x_{n+1}=a x_{n}+f_{n}, n=0,1,2, \ldots,
$$

where $a, b, f_{n} \in \mathbb{Z}, b \neq \pm 1$ and $a$ and $b$ are coprime, which has infinitely many solutions over $\mathbb{Q}$, may have either no integer solution or exactly one.

It is proven that there exists a unique solution from the ring of $p$-adic integers $\mathbb{Z}_{p}$ and this solution is found explicitly as a sum of series converging in $\mathbb{Z}_{p}$ with respect to the well-known non-Archimedean valuation (see [1, Cor.2.1]).

In [2] it is shown that this unique solution can be found using the Cramer's rule. In [3] both these results are generalized for the second order equation.

Let us consider the similar equation over the ring of polynomials with the coefficients from some field $K$ :

$$
b(z) x_{n+1}(z)=a(z) x_{n}(z)+f_{n}(z), n=0,1,2, \ldots,
$$

where $a(z), b(z), f_{n}(z) \in K[z], \operatorname{deg} b \geq 1$.

Since for obtaining the solution over $\mathbb{Z}$ we considered the equation over the completion of $\mathbb{Z}$, i.e. $\mathbb{Z}_{p}$, then for obtaining the solution over $K[z]$ it is naturally to consider the equation over the completion of $K[z]$, i.e. $K[[z]]$. This analogy is described, for instance, in $[4, \S 7]$.

In the present article a construction integrating these two cases is described: the ring of $p$-adic integers is a particular case of the valuation ring of a field with a non-Archimedean valuation $\mathbb{Q}_{p}$, the ring of formal power series also is a valuation ring of a field of formal Laurent series ([5, Ch. XII, §6]).

The results for the finding a solution of such an equation over the ring of integers are generalized to an equation of the arbitrary order and for the class of rings, which are valuation rings of non-Archimedean field. The results obtained in this article also clarify the previous results for integers.

In Theorems 1 and 2 of Section 2 a sufficient conditions for the uniqueness and existence of a solution of $n$-th order difference equation over the valuation ring of a field with a non-Archimedean valuation is formulated. The solution is explicitly found as a sum of the series (see Theorem 2), converging with respect to the non-Archimedean valuation in the field. In Section 3 it is shown that this unique solution can be found using the Cramer's rule.

Section 4 is devoted to the equations over the ring of polynomials. The results of Section 2, applied to the equations over the field of formal power series (Corollaries 2 and 3), require some additional study to check the existence of a polynomial solution. There is given Theorems 4, 5 and 6 , facilitating this checking in different particular situations and some specific examples of its applying.

\section{Existence and uniqueness theorems}

Consider a field $F$ with a non-Archimedean valuation $|\cdot|$ (see $[6,1.2])$ and its valuation $\operatorname{ring} R=\{s \in F:|s| \leq 1\}$ (see [5, Ch. XII, §4]). 
Theorem 1. Suppose $a_{j} \in R,\left|a_{j}\right|<\left|a_{0}\right|$ for all $1 \leq j \leq m$, and $f_{n} \in R$ for $n=0,1,2, \ldots$ Then the following implicit difference equation

$$
a_{m} w_{n+m}+a_{m-1} w_{n+m-1}+\ldots+a_{1} w_{n+1}+a_{0} w_{n}=f_{n}, n=0,1,2, \ldots
$$

has no more than one solution over $R$.

Proof. To prove the uniqueness of solution of the equation (1) it is enough to proof that the homogeneous equation

$$
a_{m} w_{n+m}+a_{m-1} w_{n+m-1}+\ldots+a_{1} w_{n+1}+a_{0} w_{n}=0, n=0,1,2, \ldots
$$

has only trivial solution $w_{n}=0$ for any $n$ over $R$.

Over the field $F$ the solution $\left\{w_{n}\right\}$ satisfies

$$
w_{n}=-\frac{a_{m}}{a_{0}} w_{n+m}-\frac{a_{m-1}}{a_{0}} w_{n+m-1}-\ldots-\frac{a_{1}}{a_{0}} w_{n+1}, n=0,1,2, \ldots
$$

Then, taking into account that the valuation is non-Archimedean, we obtain $\left|w_{n}\right| \leq \max _{1 \leq i \leq m}\left\{\left|\frac{a_{i} w_{n+i}}{a_{0}}\right|\right\}$. Therefore for any $n$ there is $i$ such that $\left|\frac{a_{i} w_{n+i}}{a_{0}}\right| \geq\left|w_{n}\right|$. By $r$ denote $\max _{1 \leq j \leq m}\left\{\left|\frac{a_{j}}{a_{0}}\right|\right\}$. Note that by assumptions of the theorem, $r<1$. We obtain that for any $n$ there is $i$ such that $\left|w_{n}\right| \leq r\left|w_{n+i}\right|$.

Thus starting with $w_{0}$ one can construct a subsequence $\left\{w_{n_{i}}\right\}$ such that $n_{0}=0$ and $\left|w_{n_{i}}\right| \leq r\left|w_{n_{i+1}}\right|$ for all $i$. It means that $\left|w_{0}\right| \leq r^{i} \cdot\left|w_{n_{i}}\right|$ for any $i$. Since $\left|w_{n}\right|$ belongs to $R$ then $\left|w_{n}\right| \leq 1$ for all $n$, then $\left|w_{0}\right| \leq r^{i}$ for any $i$. Note also that by the assumption of the theorem, $r<1$. Thus $w_{0}=0$ and consequently $w_{n}=0$ for all $n$.

The proof is complete.

Remark 3.1. Suppose $R_{0}$ is a factorial ring, $v \in R_{0}$ is a prime element (/5, Ch.XII, 4]). Then any element $x$ from the field of fractions $\operatorname{Frac}\left(R_{0}\right)$ has a unique representation $x=v^{t} \cdot c$ such that $t \in \mathbb{Z}$ and $c=\frac{r}{s}$, where $r, s \in R_{0}$ and both of $r$, $s$ have not $v$ in their factorizations. By definition, put $|x|_{v}=2^{-t}$. The valuation $|\cdot|_{v}$ is non-Archimedean over $\operatorname{Frac}\left(R_{0}\right)$ and $R_{0}$ is a valuation ring for $\operatorname{Frac}\left(R_{0}\right)$.

Over the ring $R_{0}$ the assumption $\left|a_{j}\right|_{v}<\left|a_{0}\right|_{v} \leq 1$ of Theorem 1 can be rewritten in the following form: if $a_{j}=v^{t_{j}} \cdot c_{j}$, where $t_{j} \in \mathbb{Z}$ and $c_{j}=\frac{r_{j}}{s_{j}}$, where $r_{j}, s_{j} \in R_{0}$ and both of $r_{j}, s_{j}$ have not $v$ in their factorizations, then $t_{j}>t_{0} \geq 0$ for all $0 \leq j \leq m$.

In this case Theorem 1 yields, for instance, the following consequence:

Corollary 1. If there exists $v \in R_{0}$ such that $v$ does not divide $a_{0}$ and $v$ divides $a_{j}$ for all $1 \leq j \leq m$, then the equation (1) has no more than one solution over $R_{0}$.

The following theorem gives a sufficient condition for the existence of solutions of Equation (1) over the ring $R$. 
Suppose conditions of Theorem 1 hold and $\left|a_{0}\right|=1$. Then $a_{0}$ is invertible in $R$. Indeed, in the field $F$ there is an element $a_{0}^{-1}$ and $\left|a_{0}^{-1}\right|=1$, thus it belongs to $R$. Thus the following infinite linear system

$$
\left\{\begin{array}{rlrl}
y_{0} & =1, \\
a_{0} y_{k}+a_{1} y_{k-1}+a_{2} y_{k-2}+\ldots+a_{k} y_{0} & =0, & k=1, \ldots, m-1 \\
a_{0} y_{k}+a_{1} y_{k-1}+a_{2} y_{k-2}+\ldots+a_{m} y_{k-m} & =0, & k=m, m+1, m+2, \ldots
\end{array}\right.
$$

is explicit. It has a unique solution $\left\{y_{n}\right\}_{n=0}^{\infty}$ over $R$. The following theorem describes a solution of (1).

Theorem 2. Let the field $F$ be complete. If $\left|a_{j}\right|<\left|a_{0}\right|=1$ for all $1 \leq j \leq m$, all the following series

$$
w_{n}=\sum_{k=0}^{\infty} y_{k} \frac{f_{n+k}}{a_{0}}, n=0,1,2, \ldots
$$

converge in $R$ with respect to the valuation $|\cdot|$. This sequence $\left\{w_{n}\right\}$ is a unique solution of (1).

Proof. The valuation $|\cdot|$ is non-Archimedean, so to prove the series (5) converge over $R$ it is enough to prove that $\left|y_{k} \frac{f_{n+k}}{a_{0}}\right|$ tends to zero. $([6,2.1])$

Since $f_{n}, a_{0}^{-1}$ both belong to $R$, then $\left|\frac{f_{n+k}}{a_{0}}\right| \leq 1$. Let us prove that $\left|y_{n}\right| \leq r^{\left[\frac{n}{m}\right]} \cdot S$, where $S=\max _{0 \leq j \leq m-1}\left\{\left|y_{j}\right|\right\}$ and $r=\max _{1 \leq j \leq m}\left\{\left|a_{j}\right|\right\}$.

The proof is by induction on $n$. For the cases $n<m$, there is nothing to proof. Indeed, $\left|y_{n}\right| \leq S=\max _{0 \leq j \leq m-1}\left\{\left|y_{j}\right|\right\}$.

For the case $n=m=m+0$, by the system (4), we get

$$
y_{m}=-\frac{a_{1}}{a_{0}} y_{m-1}-\frac{a_{2}}{a_{0}} y_{m-2}-\ldots-\frac{a_{m}}{a_{0}} y_{0},
$$

so, keeping in mind that $|\cdot|$ is non-Archimedean and $\left|a_{0}\right|=1$, we can estimate

$$
\left|y_{m}\right|=\left|\frac{a_{1}}{a_{0}} y_{m-1}+\frac{a_{2}}{a_{0}} y_{m-2}+\ldots+\frac{a_{m}}{a_{0}} y_{0}\right| \leq \max _{1 \leq j \leq m}\left\{\left|a_{j} y_{m-j}\right|\right\} \leq r \cdot S .
$$

For the inductive step assume that the inequality holds for $n \leq m+k-1$. Let us prove that it holds also for $n=m+k$, i.e. $\left|y_{n}\right| \leq r^{\left[\frac{k+m}{m}\right]} \cdot S$.

By the system (4), we get

$$
y_{k+m}=-\frac{a_{1}}{a_{0}} y_{k+m-1}-\frac{a_{2}}{a_{0}} y_{k+m-2}-\ldots-\frac{a_{m}}{a_{0}} y_{k},
$$

so, keeping in mind that $|\cdot|$ is non-Archimedean and $\left|a_{0}\right|=1$, we can estimate

$$
\left|y_{k+m}\right| \leq \max _{1 \leq j \leq m}\left\{\left|a_{j} y_{k+m-j}\right|\right\} \leq r \cdot \max _{1 \leq j \leq m}\left\{\left|y_{k+m-j}\right|\right\}
$$


By the inductive assumptions, $\left|y_{j}\right| \leq r^{\left[\frac{j}{m}\right]} \cdot S \leq r^{\left[\frac{k}{m}\right]} \cdot S$ for all $k \leq j \leq k+m-1$, that is $\max _{1 \leq j \leq m}\left\{\left|y_{k+m-j}\right|\right\} \leq r^{\left[\frac{k}{m}\right]} \cdot S$. It follows that $\left|y_{k+m}\right| \leq r \cdot r^{\left[\frac{k}{m}\right]} \cdot S=r^{\left[\frac{k+m}{m}\right]} \cdot S$.

Therefore, by the principle of induction, the inequality $\left|y_{n}\right| \leq r^{\left[\frac{n}{m}\right]} \cdot S$ is true for any $n \in \mathbb{N}_{0}$.

Since $r<1$, then $\left|y_{n}\right|$ tends to 0 , so the series (5) converges.

To verify that (5) satisfies (1), let us substitute it into the equation. Taking into account that $\left\{y_{n}\right\}_{n=0}^{\infty}$ satisfies (4), we obtain

$$
\begin{array}{r}
a_{m} w_{n+m}+a_{m-1} w_{n+m-1}+\ldots+a_{1} w_{n+1}+a_{0} w_{n}=\frac{1}{a_{0}} \sum_{i=0}^{m} \sum_{k=0}^{\infty} a_{i} y_{k} f_{n+k+i}= \\
=\frac{1}{a_{0}} \sum_{i=0}^{m-1} f_{i+n} \sum_{j=0}^{i} a_{j} y_{i-j}+\frac{1}{a_{0}} \sum_{i=m}^{\infty} f_{i+n} \sum_{j=0}^{m} a_{j} y_{i-j}=f_{n} .
\end{array}
$$

The proof is complete.

Remark 3.2. In the particular case $m=1$ we have the equation

$$
a_{1} w_{n+1}+a_{0} w_{n}=f_{n}, n=0,1,2, \ldots,
$$

which has a unique solution over $R$ if $\left|a_{0}\right|=1$ and $\left|a_{1}\right|<1$. By Theorem 1, this solution has the form of series (5). In this case (4) has a solution

$$
y_{k}=(-1)^{k} \frac{a_{1}^{k}}{a_{0}^{k}}, k=0,1,2, \ldots,
$$

so the solution of (7) can be written as

$$
w_{n}=\sum_{k=0}^{\infty}(-1)^{k} \frac{a_{1}^{k}}{a_{0}^{k+1}} f_{n+k}, n=0,1,2, \ldots,
$$

In the particular case $R=\mathbb{Z}_{p}$ this result is obtained in [1].

Remark 3.3. The case $m=2$ is described in details over the ring of integers in [3].

\section{Cramer formulas}

Suppose $F$ is a field of characteristic zero with a non-Archimedean valuation $|\cdot|$ and for the equation (1) conditions of Theorem 2 hold. Then it has a unique solution over $R$, which can be found using Cramer's rule.

Since $a_{0}$ is invertible, without loss of generality one can consider the following equation instead of (1):

$$
a_{m} w_{n+m}+a_{m-1} w_{n+m-1}+\ldots+a_{1} w_{n+1}+w_{n}=f_{n}, n=0,1,2, \ldots
$$


It can be written as a system of linear equations in this way:

$$
\mathcal{A} w=f, \mathcal{A}=\left(\begin{array}{ccccccccc}
1 & a_{1} & a_{2} & a_{3} & \cdots & a_{m} & 0 & 0 & \cdots \\
0 & 1 & a_{1} & a_{2} & \cdots & a_{m-1} & a_{m} & 0 & \cdots \\
0 & 0 & 1 & a_{1} & \cdots & a_{m-2} & a_{m-1} & a_{m} & \cdots \\
\vdots & \vdots & \vdots & \vdots & \ddots & \vdots & \vdots & \vdots & \ddots
\end{array}\right), f=\left(\begin{array}{c}
f_{0} \\
f_{1} \\
f_{2} \\
\vdots
\end{array}\right)
$$

Let $\mathcal{A}_{n}$ be obtained from the matrix $\mathcal{A}$ by replacing the $n$-th column with the vector $f$.

By $\Delta_{j}$ (respectively, $\Delta_{n, j}$ ) denote the principal corner minor of the $(j+1)$ th order of the matrix $\mathcal{A}$ (respectively, $\mathcal{A}_{n}$ ).

Theorem 3. Suppose the conditions of Theorem 2 hold. Then the unique solution over $R$ can be found using Cramer's rule:

$$
w_{n}=\frac{\operatorname{det} \mathcal{A}_{n}}{\operatorname{det} \mathcal{A}}, n=0,1,2, \ldots
$$

where the determinants are defined as following limits in $R$ with the valuation $|\cdot|$ :

$$
\begin{gathered}
\operatorname{det} \mathcal{A}=\lim _{r \rightarrow \infty} \Delta_{r}, \\
\operatorname{det} \mathcal{A}_{n}=\lim _{r \rightarrow \infty} \Delta_{n+1, r}, n=0,1,2, \ldots
\end{gathered}
$$

Proof. By Theorems 1 and 2, equation (1) has a unique solution over $R$ in the form (5). Let us show that this solution coincides with the Cramer formulas (10). Note that $\Delta_{j}=1$ for all $j$, so $\operatorname{det} \mathcal{A}=1$. Let us consider

$$
\mathcal{A}_{1}=\left(\begin{array}{ccccccccc}
f_{0} & a_{1} & a_{2} & a_{3} & \cdots & a_{m} & 0 & 0 & \cdots \\
f_{1} & 1 & a_{1} & a_{2} & \cdots & a_{m-1} & a_{m} & 0 & \cdots \\
f_{3} & 0 & 1 & a_{1} & \cdots & a_{m-2} & a_{m-1} & a_{m} & \cdots \\
\vdots & \vdots & \vdots & \vdots & \ddots & \vdots & \vdots & \vdots & \ddots
\end{array}\right)
$$

Denote by $B_{k}$ the determinant formed by the first $k$ columns and rows of the matrix

$$
\left(\begin{array}{cccccc}
a_{1} & a_{2} & \cdots & a_{m} & 0 & 0 \\
1 & a_{1} & \cdots & a_{m-1} & a_{m} & 0 \\
0 & 1 & \cdots & a_{m-2} & a_{m-1} & a_{m} \\
0 & 0 & \cdots & a_{m-3} & a_{m-2} & a_{m-1} \\
\vdots & \vdots & \ddots & \vdots & \vdots & \vdots
\end{array}\right) .
$$

Add also $B_{0}=1$. If $0<k<m$ it is written as

$$
B_{k}=\left|\begin{array}{ccccc}
a_{1} & a_{2} & \cdots & a_{k-1} & a_{k} \\
1 & a_{1} & \cdots & a_{k-2} & a_{k-1} \\
0 & 1 & \cdots & a_{k-3} & a_{k-2} \\
\vdots & \vdots & \ddots & \vdots & \vdots \\
0 & 0 & \cdots & a_{1} & a_{2} \\
0 & 0 & \cdots & 1 & a_{1}
\end{array}\right| .
$$


Considering the $\Delta_{1, j}$ and decomposing it relative to the first column, we get the partial sums of

$$
\operatorname{det} \mathcal{A}_{1}=f_{0}+\sum_{j=1}^{m}(-1)^{j} f_{j} B_{j}
$$

We should prove that the right-hand side of this formula coincides with $\sum_{k=0}^{r} y_{k} f_{k}$, so we should prove that $y_{k}=(-1)^{k} B_{k}$ if $k \geq 1$.

Recurrence equations

$$
\left\{\begin{aligned}
y_{k}+a_{1} y_{k-1}+a_{2} y_{k-2}+\ldots+a_{k} y_{0}=0, & k=1, \ldots, m-1 \\
y_{k}+a_{1} y_{k-1}+a_{2} y_{k-2}+\ldots+a_{m} y_{k-m}=0, & k=m, m+1, m+2, \ldots
\end{aligned}\right.
$$

with the initial condition $y_{0}=1$ give a unique sequence $\left\{y_{k}\right\}_{k=0}^{\infty}$. Thus we should prove that $\left\{(-1)^{k} B_{k}\right\}_{k=0}^{\infty}$ is a solution of these equations too.

Decomposing $B_{k}$ relative to the first row, we get

$$
\begin{cases}B_{k}=a_{1} B_{k-1}-a_{2} B_{k-2}+a_{3} B_{k-3}-\ldots+(-1)^{m-1} a_{m} B_{k-m}, & \text { if } k \geq m \\ B_{k}=a_{1} B_{k-1}-a_{2} B_{k-2}+a_{3} B_{k-3}-\ldots+(-1)^{k} a_{k} B_{0}, & \text { if } k<m\end{cases}
$$

Hence,

$$
\begin{cases}B_{k}-a_{1} B_{k-1}+a_{2} B_{k-2}-a_{3} B_{k-3}-\ldots+(-1)^{k+1} a_{k} B_{0}=0, & \text { if } k<m \\ B_{k}-a_{1} B_{k-1}+a_{2} B_{k-2}-a_{3} B_{k-3}+\ldots+(-1)^{m} a_{m} B_{k-m}=0, & \text { if } k \geq m\end{cases}
$$

It follows that $\left\{(-1)^{k} B_{k}\right\}_{k=0}^{\infty}$ is a solution of (11). Thus $y_{k}=(-1)^{k} B_{k}$ for any $k$, therefore $\operatorname{det} \mathcal{A}_{1}=w_{0}$.

Now consider $\mathcal{A}_{j}$ and its minor of $i$-th order. Note that we are interested in the limit by $i$, so it is enough to consider $i$ such that $i>j$ and $i>m$.

$$
\left(\begin{array}{cccccc|cccccc}
1 & a_{1} & a_{2} & \cdots & a_{j-2} & a_{j-1} & f_{0} & a_{j+1} & \cdots & a_{m} & 0 & \cdots \\
0 & 1 & a_{1} & \cdots & a_{j-3} & a_{j-2} & f_{1} & a_{j} & \cdots & a_{m-1} & a_{m} & \cdots \\
0 & 0 & 1 & \cdots & a_{j-4} & a_{j-3} & f_{2} & a_{j-1} & \cdots & a_{m-2} & a_{m-1} & \cdots \\
\vdots & \vdots & \vdots & \ddots & \vdots & \vdots & \vdots & \vdots & \ddots & \vdots & \vdots & \ddots \\
0 & 0 & 0 & \cdots & 1 & a_{1} & f_{j-1} & a_{3} & \cdots & a_{m-j-1} & a_{m-j} & \cdots \\
0 & 0 & 0 & \cdots & 0 & 1 & f_{j} & a_{2} & \cdots & a_{m-j-2} & a_{m-j-1} & \cdots \\
\hline 0 & 0 & 0 & \cdots & 0 & 0 & f_{j+1} & a_{1} & \cdots & a_{m-j-3} & a_{m-j-2} & \cdots \\
0 & 0 & 0 & \cdots & 0 & 0 & f_{j+2} & 1 & \cdots & a_{m-j-4} & a_{m-j-3} & \cdots \\
0 & 0 & 0 & \cdots & 0 & 0 & f_{j+3} & 0 & \cdots & a_{m-j-5} & a_{m-j-4} & \cdots \\
\vdots & \vdots & \vdots & \ddots & \vdots & \vdots & \vdots & \vdots & \ddots & \vdots & \vdots & \ddots
\end{array}\right)
$$

We see that its determinant equals $\operatorname{det} \mathcal{A}_{1}$, in which the vector $\left(f_{j+1}, f_{j+2}, f_{j+3}, \ldots\right)^{\top}$ is taken instead of $f$. It follows that $\Delta_{j, i}=\sum_{k=0}^{i} y_{k} f_{j+k}$, so $\operatorname{det} \mathcal{A}_{j}=\sum_{k=0}^{\infty} y_{k} f_{j+k}$. 
The proof is complete.

\section{Implicit linear difference first-order equation over the ring of polynomials}

Let $K$ be a field with the characteristic zero. For any $z_{0} \in K$ we can consider the ring of formal power series $K\left[\left[z-z_{0}\right]\right]$. It is a factorial ring ([5, Ch.IV, Th.9.3.]), so we can construct its field of fractions and valuation ring as in Remark 3.1. This field of fractions is a field of Laurent series $K\left(\left(z-z_{0}\right)\right)$, it is complete. By definition, for $w \in K\left(\left(z-z_{0}\right)\right)$ put $\left|w\left(z-z_{0}\right)\right|_{z-z_{0}}=2^{t}$, where $t$ is the smallest integer for that $\left(z-z_{0}\right)^{t} \cdot w\left(z-z_{0}\right) \in K\left[\left[z-z_{0}\right]\right]$ (see [5, Ch.XII, §6]).

Then Theorems 1 and 2 yield the following corollaries:

Corollary 2. Let us consider the equation

$$
b\left(z-z_{0}\right) w_{n+1}\left(z-z_{0}\right)+f_{n}\left(z-z_{0}\right)=a\left(z-z_{0}\right) w_{n}\left(z-z_{0}\right), n=0,1,2, \ldots,
$$

where $b\left(z-z_{0}\right), a\left(z-z_{0}\right), f_{n}\left(z-z_{0}\right) \in K\left[\left[z-z_{0}\right]\right]$.

Suppose $a\left(z-z_{0}\right)=\left(z-z_{0}\right)^{k} \cdot a_{1}\left(z-z_{0}\right)$ and $b\left(z-z_{0}\right)=\left(z-z_{0}\right)^{m} \cdot b_{1}\left(z-z_{0}\right)$, where $a_{1}\left(z_{0}\right) \neq 0, b_{1}\left(z_{0}\right) \neq 0$ and $k, m$ are non-negative integers. If $k<m$, then there exists at most one sequence of formal power series $\left\{w_{n}\left(z-z_{0}\right)\right\}$ that satisfies (12).

Corollary 3. Suppose $a\left(z_{0}\right) \neq 0$ and $b\left(z_{0}\right)=0$. Then the sequence of series

$$
w_{n}\left(z-z_{0}\right)=\sum_{i=0}^{\infty} \frac{b^{i}\left(z-z_{0}\right)}{a^{i+1}\left(z-z_{0}\right)} f_{n+i}\left(z-z_{0}\right), n=0,1,2, \ldots
$$

is a unique solution of (12) over $K\left[\left[z-z_{0}\right]\right]$.

Two previous results are related to the solution in the ring of formal power series. They imply also the following result, concerning the solution over the ring of polynomials.

Suppose $a(z), b(z), f_{n}(z) \in K[z]$. Let us consider the equation

$$
b(z) w_{n+1}(z)+f_{n}(z)=a(z) w_{n}(z), n=0,1,2, \ldots
$$

Since any polynomial can be rewritten as a formal power series from $K\left[\left[z-z_{0}\right]\right]$ for any $z_{0}$, then this equation can be consider over $K\left[\left[z-z_{0}\right]\right]$ for any $z_{0}$.

Corollary 4. If for some $z_{0}$ Equation (14), considering over $K\left[\left[z-z_{0}\right]\right]$, satisfies the assumptions of Corollary 2, then Equation (14) has no more than one polynomial solution. If also the conditions of Corollary 3 hold for this $z_{0}$, then either sequence of sums

$$
w_{n}(z)=\sum_{i=0}^{\infty} \frac{b^{i}(z)}{a^{i+1}(z)} f_{n+i}(z), n=0,1,2, \ldots,
$$

is a sequence of polynomials that solves (14) or there is no polynomial solution of (14). 
Proof. By Corollary 2, Equation (14) has no more than one formal power series solution (15). It is only candidate for being the polynomial solution.

The following example shows that it may be no polynomial solution of Equation (14).

Example 1. The equation

$$
z w_{n+1}+1=w_{n}, n=0,1,2, \ldots,
$$

has no polynomial solution. Indeed, we are under the conditions of Corollary 4, so there is unique formal power series solution $w_{n}(z)=1+z+z^{2}+z^{3}+\ldots$ for all $n$, which obviously is not a polynomial.

The following theorem directly follows from Corollary 4 if $K$ is algebraically closed. In the general case it needs a proof.

Theorem 4. The homogeneous equation

$$
b(z) w_{n+1}(z)=a(z) w_{n}(z), n=0,1,2, \ldots
$$

has only zero solution if and only if $b(z)$ does not divide $a(z)$. Thus Equation (14) has at most one polynomial solution if $b(z)$ does not divide $a(z)$.

Proof. Indeed, since $b(z)$ does not divide $a(z)$, there exists $p(z) \in K[z]$ such that $p(z)$ divides $b(z)$ but does not divide $a(z)$. Also, (16) means that

$$
\frac{b^{n}(z)}{a^{n}(z)} w_{n}(z)=w_{0}(z), n=0,1,2, \ldots
$$

We get that $w_{0}(z)$ is divisible by $p^{n}(z)$ for any degree $n$, which is impossible for a non-zero element $w_{0}(z)$. Since $w_{0}(z)=0$, then $w_{n}(x)=0$ for any $n$.

If $b(z)$ divides $a(z)$, then the equation (14) can be rewritten in an explicit form. It follows that there exist infinitely many solutions of this equation: one for each initial value $w_{0}$.

The proof is complete.

Example 2. Suppose $f_{n}(z)=f(z)$ for each $n$, and suppose $b(z)$ does not divide $a(z)$. Suppose there exists a solution $\left\{w_{n}\right\}$ of the difference equation

$$
b(z) w_{n+1}(z)+f(z)=a(z) w_{n}(z) .
$$

Consider the sequence $\left\{w_{n+1}\right\}$. Obviously, it also satisfies these equalities. By the uniqueness of the solution, we get $w_{n}=w_{n+1}$ for all $n$. It means that if the solution exists, it is constant. Therefore, it should satisfy the equality

$$
b(z) w(z)+f(z)=a(z) w(z),
$$

so we obtain that 


$$
w_{n}(z)=w(z)=\frac{f(z)}{a(z)-b(z)}
$$

is the only candidate to be a solution, thus there exists a solution if and only if $a(z)-b(z)$ divides $f(z)$.

Particularly the equation $z w_{n+1}+1=w_{n}, n=0,1,2, \ldots$ from the previous example has no polynomial solution since $b(z)-a(z)=1-z$ does not divide $f(z)=1$.

The example considered shows that the equation may have no polynomial solution, and to check that using Corollary 4, one have to check whether the sequence of formal power series (15) is a sequence of polynomials. The following result gives that it is enough to check whether only the first term $w_{0}(z)$ is a polynomial.

Theorem 5. Suppose $a(z)=1$. If the $w_{0}$ from (15) is a polynomial, then $w_{n}$ from (15) is a polynomial for any $n$.

Proof. Let us prove this by induction. Since $\left\{w_{n}\right\}$ satisfies the equation, then

$$
w_{n+1}(z)=\frac{w_{n}(z)-f_{n}(z)}{b(z)}, n=0,1,2, \ldots
$$

Since $w_{n}(z)$ and $f_{n}(z)$ both are polynomials, then $w_{n}(z)-f_{n}(z)$ is a polynomial too. Let us prove that $b(z)$ divides it. By (15), we get

$w_{n}(z)-f_{n}(z)=b(z)\left(f_{n+1}(z)+b(z) f_{n+2}(z)+b^{2}(z) f_{n+3}(z)+\ldots\right), n=0,1,2, \ldots$

Let us choose $\tilde{z}$ from the algebraic closure $\tilde{K}$ of $K$ such that $z-\tilde{z}$ divides $b(z)$. Then $b(\tilde{z})=0$.

Let $\hat{b}(z-\tilde{z})=b(z)$ and $\hat{f}_{n}(z-\tilde{z})=f_{n}(z)$ for any $n$. Find the $\left\{w_{n}(z)\right\}$ as a sequence of formal power series $\hat{w}_{n}(z-\tilde{z})$ from $\tilde{K}[[z-\tilde{z}]]$. Then for any $n$ we obtain an equality between two formal power series from $\tilde{K}[[z-\tilde{z}]]$ :

$$
\hat{b}(z-\tilde{z}) \sum_{i=0}^{\infty} \hat{b}^{i}(z-\tilde{z}) \hat{f}_{n+i+1}(z-\tilde{z})=\hat{w}_{n}(z-\tilde{z})-\hat{f}_{n}(z-\tilde{z}) .
$$

Since $b(\tilde{z})=0$, then $\hat{b}(0)=0$. Thus $w_{n}(\tilde{z})-f_{n}(\tilde{z})=\hat{w}_{n}(0)-\hat{f}_{n}(0)=0$, it means that $z-\tilde{z}$ divides the polynomial $w_{n}(z)-f_{n}(z)$. So we can divide this equality by $z-\tilde{z}$ and consider the equality

$$
\frac{\hat{b}(z-\tilde{z})}{z-\tilde{z}} \sum_{i=0}^{\infty} \hat{b}^{i}(z-\tilde{z}) \hat{f}_{n+i+1}(z-\tilde{z})=\frac{\hat{w}_{n}(z-\tilde{z})-\hat{f}_{n}(z-\tilde{z})}{z-\tilde{z}},
$$

where the right-hand side is a polynomial with coefficients from $\tilde{K}$. 
Repeating this for each divisor of $b(z)$, we obtain

$\sum_{i=0}^{\infty} \hat{b}^{i}(z-\tilde{z}) \hat{f}_{n+i+1}(z-\tilde{z})=\frac{\hat{w}_{n}(z-\tilde{z})-\hat{f}_{n}(z-\tilde{z})}{\hat{b}(z-\tilde{z})}=\frac{w_{n}(z)-f_{n}(z)}{b(z)}=w_{n+1}(z)$,

is a polynomial with coefficients from the algebraic closure of $K$.

We claim that its coefficients belong to $K$. Indeed, polynomials $w_{n}(z)-f_{n}(z)$ and $b(z)$ have coefficients from $K$. Let $k$ denote a degree of $w_{n+1}(z)$. Then consider $k+1$ pairwise different elements $x_{0}, x_{1}, x_{2}, \ldots, x_{k} \in K$ that are not roots of the polynomial $b(z)$. Elements $\frac{w_{n}\left(x_{j}\right)-f_{n}\left(x_{j}\right)}{b\left(x_{j}\right)} \in K$, where $0 \leq j \leq k$, are the values of our polynomial. There is a unique polynomial of degree $k$ that takes these $k+1$ values, and it has coefficients from $K$.

The proof is complete.

Remark 3.4. In fact, the equality (17) does not yield that $b(z)$ divides $w_{n}(z)-f_{n}(z)$ : it is possible that the polynomial does not divide the product of this polynomial and a formal power series, for example,

$$
(1-z)\left(1+z+z^{2}+z^{3}+\ldots\right)=1 .
$$

By Theorem 3, the formal power series considered has a special structure $f_{n}(z)+b(z) f_{n+1}(z)+b^{2}(z) f_{n+2}(z)+\ldots$, this is what allows us to carry out further reasoning.

Example 3. Let us consider the equation

$$
z w_{n+1}(z)+\sum_{j=0}^{k} A_{j} z^{n+j}=w_{n}(z) .
$$

In this case $a(z)=1, b(z)=z$ and $f_{n}(z)=\sum_{j=0}^{k} A_{j} z^{n+j}$. Then we are under the conditions of Corollaries 2, 3 and Theorem 5 over the ring $K[[z]]$. Then the first element of the solution sequence is

$$
\begin{aligned}
w_{0}(z)=\sum_{i=0}^{\infty} z^{i} \sum_{j=0}^{k} A_{j} z^{j}=\sum_{j=0}^{k} A_{j} \sum_{i=0}^{\infty} z^{i+j}=\sum_{j=0}^{k} A_{j} \sum_{i=j}^{\infty} z^{i}= \\
=\sum_{j=0}^{k} A_{j}\left(\sum_{i=j}^{k} z^{i}+\sum_{i=k+1}^{\infty} z^{i}\right)=\sum_{j=0}^{k} A_{j} \sum_{i=j}^{k-1} z^{i}+\sum_{j=0}^{k} A_{j} \cdot \sum_{i=k+1}^{\infty} z^{i}
\end{aligned}
$$

It is a polynomial if and only if $\sum_{j=0}^{k} A_{j}=0$. Then $w_{0}(z)=\sum_{j=0}^{k} A_{j} \sum_{i=j}^{k-1} z^{i}$. Theorem 5 implies that under this condition $w_{n}(z)$ also are polynomials.

It is interesting to note that the condition, which is an analogue to this one, is appeared in [7] due to the finding a rational solution of some type of difference functional equations ([7, Theorem 2]). 
Example 4. Let us consider the equation

$$
(z-1) w_{n+1}(z)+A_{n} z+B_{n}=w_{n}(z) .
$$

In this case $a(z)=1, b(z)=z-1, f_{n}(z)=A_{n} z+B_{n}$. we are under the conditions of Corollaries 2, 3 and Theorem 5 over the ring $K[[z-1]]$. Rewriting $f_{n}(z)$ as a power series from $K[[z-1]]$, we get $f_{n}(z)=A_{n}(z-1)+A_{n}+B_{n}$

Then the first power series of the solution sequence is

$$
\begin{gathered}
w_{0}(z)=\sum_{i=0}^{\infty}\left(A_{i} z+B_{i}\right)(z-1)^{i}=\sum_{i=0}^{\infty}\left(A_{i}(z-1)^{i+1}+\left(A_{i}+B_{i}\right)(z-1)^{i}\right)= \\
=\sum_{i=1}^{\infty} A_{i-1}(z-1)^{i}+\sum_{i=0}^{\infty}\left(A_{i}+B_{i}\right)(z-1)^{i}=A_{0}+B_{0}+\sum_{i=1}^{\infty}\left(A_{i-1}+A_{i}+B_{i}\right)(z-1)^{i}
\end{gathered}
$$

It is a polynomial if and only if there is $j$ such that for any $i \geq j$ the condition $A_{i-1}+A_{i}+B_{i}=0$ holds. Theorem 5 implies that in this case $w_{n}(z)$ also are polynomials.

For checking whether the formal power series solution of (14) is a sequence of polynomials, one can look at degrees.

Example 5. The equation $z w_{n+1}+1=w_{n}$ has no polynomial solution, because $\operatorname{deg} w_{n}(z)=\operatorname{deg} w_{n+1}(z)+1$, so the degree of $w_{n}(z)$ decreases, which is impossible for a sequence of polynomials.

The following theorem provides general information about the degree of a polynomial solution, which is useful either for finding it or for proving the non-existence.

Theorem 6. Suppose $\operatorname{deg} a<\operatorname{deg} b$. If the sequence of polynomials $w_{n}(z)$ is a solution of Equation (14), then there exists some number $k$ such that the inequality

$$
\operatorname{deg} w_{k} \leq \operatorname{deg} f_{k}-\operatorname{deg} b+\operatorname{deg} a
$$

holds.

Proof. Assume the converse, then $\operatorname{deg} w_{k}>\operatorname{deg} f_{k}-\operatorname{deg} b+\operatorname{deg} a$ for all $k$. Let us consider the following cases, keeping in mind that $\left\{w_{k}\right\}$ satisfies (14):

1. if $\operatorname{deg} f_{k}<\operatorname{deg} w_{k+1}+\operatorname{deg} b$, then $\operatorname{deg} w_{k}+\operatorname{deg} a=\operatorname{deg} w_{k+1}+\operatorname{deg} b$;

2. if $\operatorname{deg} f_{k}=\operatorname{deg} w_{k+1}+\operatorname{deg} b$, then $\operatorname{deg} w_{k+1}=\operatorname{deg} f_{k}-\operatorname{deg} b<\operatorname{deg} w_{k}-\operatorname{deg} a$;

3. if $\operatorname{deg} f_{k}>\operatorname{deg} w_{k+1}+\operatorname{deg} b$, then $\operatorname{deg} w_{k}+\operatorname{deg} a=\operatorname{deg} f_{k}>\operatorname{deg} w_{k+1}+\operatorname{deg} b$.

In all these cases we conclude that $\operatorname{deg} w_{k+1}<\operatorname{deg} w_{k}$ for any $k$. The sequence of degrees of $w_{k}(z)$ decreases, which is impossible for a sequence of polynomials' degrees.

The proof is complete. 
Example 6. Let us consider the equation

$$
(z+1) w_{n+1}+A z^{n}+B z^{n+1}+C z^{n+2}+D z^{n+3}=w_{n}(z) .
$$

In this case $a(z)=1, b(z)=z+1, f_{n}(z)=A z^{n}+B z^{n+1}+C z^{n+2}+D z^{n+3}$. We are under the conditions of Corollaries 2 and 3 over the ring $K[[z+1]]$, thus we can write down the solution:

$$
w_{n}(z)=\sum_{i=0}^{\infty}\left(A z^{n}+B z^{n+1}+C z^{n+2}+D z^{n+3}\right)(z+1)^{i}
$$

To check whether these series are polynomials directly, one needs either to rewrite $f_{n}(z)$ as a power series from $K[[z+1]]$, or to rewrite $b^{i}(z)$ as a power series from $K[[z]]$. It is not easy to do both.

By Theorem 6 , if $w_{n}(z)$ is a polynomial, then for some $n$ its degree is no more than $\operatorname{deg}\left(A z^{n}+B z^{n+1}+C z^{n+2}+D z^{n+3}\right)-\operatorname{deg}(z+1)=n+2$. It means that if the polynomial solution exists, all terms of this sum having a greater degree are reduced. The terms having a less degree are only in the first three summands, we are not interested in others.

Thus if the equation considered has a polynomial solution, it may be the sum of terms with degree no more than $n+2$ from the first three summands:

$$
w_{n}(z)=A z^{n}+(A+B) z^{n+1}+(2 A+B+C) z^{n+2}
$$

Now it is left to check when this polynomial satisfies the equation:

$$
\begin{aligned}
& (z+1)\left(A z^{n+1}+(A+B) z^{n+2}+(2 A+B+C) z^{n+3}\right)+ \\
& +A z^{n}+B z^{n+1}+C z^{n+2}+D z^{n+3}= \\
& =A z^{n}+(A+B) z^{n+1}+(2 A+B+C) z^{n+2}
\end{aligned}
$$

We get that the coefficients of $z^{n}, z^{n+1}$ and $z^{n+2}$ coincide automatically, coefficients of $z^{n+3}$ and $z^{n+4}$ give us assumptions $3 A+2 B+C+D=0$ and $2 A+B+C=0$. We conclude that the equation considered has a polynomial solution if an only if $D=A+C$ and $2 A+B+C=0$. The solution found is

$$
w_{n}(z)=A z^{n}+(A+B) z^{n+1} .
$$

Acknowledgement. The research was supported by the National Research Foundation of Ukraine funded by Ukrainian State budget in frames of project 2020.02/0096 "Operators in infinite-dimensional spaces: the interplay between geometry, algebra and topology"

ORCID ID

A. B. Goncharuk (iD) https://orcid.org/0000-0002-3562-795X 


\title{
REFERENCES
}

1. V. A. Gerasimov, S. L. Gefter, A. B. Goncharuk. Application of the p-Adic Topology on $\mathbb{Z}$ to the Problem of Finding Solutions in Integers of an Implicit Linear Difference Equation, Journal of Mathematical Sciences, - 2018. - 235. - P. 256-261. DOI: 10.1007/s10958-018-4072-x

2. S. Gefter, A. Goncharuk. Generalized backward shift operators on the ring $\mathbb{Z}[[x]]$, Cramer's rule for infinite linear systems, and p-adic integers. In: A. Böttcher, D. Potts, P. Stollmann, D. Wenzel (eds) The Diversity and Beauty of Applied Operator Theory. Operator Theory: Advances and Applications, Vol. 268. Birkhäuser, Cham., - 2018. - P. 247-259. DOI: 10.1007/9783-319-75996-8_13

3. S. L. Gefter, V. V. Martseniuk, A. B. Goncharuk, A. L. Piven'. Analogue of the Cramer Rule for an Implicit Linear Second Order Difference Equation Over the Ring of Integers, Journal of Mathematical Sciences, - 2020. - 244. P. 601-607. DOI: 10.1007/s10958-019-04635-w

4. I. R. Shafarevich. Basic Notions of Algebra. In: A. I. Kostrikin, I. R. (eds) Algebra I. Encyclopaedia of Mathematical Sciences. 1990. Springer, Berlin, Heidelberg, 258 p. DOI: 10.1007/978-3-662-39643-8_1

5. S. Lang. Algebra. 2002. Springer-Verlag, New York, XV+918 p. DOI: 10.1007/978-1-4613-0041-0

6. C. Perez-Garcia, W. H. Schikhof. Locally Convex Spaces over NonArchimedean Valued Fields. 2010. Cambridge University Press, 472 p. DOI: $10.1017 /$ CBO9780511729959

7. A. I. Derevianko, S. L. Gefter. Rational Solutions of the Simplest Linear Inhomogeneous Difference Equations, Theoretical and Applied Aspects of Cybernetics, Proceedings of the 5th International Scientific Conference of Students and Young Scientists. 2015. Bukrek, Kyiv. P. 117-122.

\author{
Неявні лінійні різницеві рівняння \\ над неархімедовими кільцями \\ Гончарук А. Б. \\ Харківсъкий національний університет імені В. Н. Каразіна \\ м. Свободи, 4, Харків, Украӥна, 61022
}

Над будь-яким полем неявне лінійне різницеве рівняння зводиться до звичайного явного, яке має нескінченно багато розв'язків - свій для кожного початкового значення. Цікаво розглянути неявне різницеве рівняння над кільцем, оскільки над будь-яким кільцем випадок неявного рівняння значно відрізняється від випадку явного. Результати щодо різницевих рівнянь над кільцями, що були отримані раніше, здебільшого стосуються кільця цілих чисел і рівнянь першого та другого порядку. 
У цій статті вивчаються неявні різницеві рівняння високого порядку над деякими іншими класами кілець, зокрема, над кільцем поліномів.

Для вивчення різницевого рівняння над кільцем цілих чисел корисною була ідея розглянути цілі $p$-адичні числа - поповнення кільця цілих чисел щодо неархімедової $p$-адичної норми. Щоб знаходити розв'язок неявного різницевого рівняння над кільцем поліномів, природним буде розглянути таку ж конструкцію для цього кільця: кільце формальних степеневих рядів, яке є поповненням кільця поліномів щодо неархімедової норми.

Кільце формальних степеневих рядів та кільце цілих $p$-адичних чисел - це окремі випадки кільця нормування щодо неархімедової норми деякого поля: поля рядів Лорана та поля $p$-адичних раціональних чисел відповідно. У цій статті вивчається неявне лінійне різницеве рівняння над кільцем нормування довільного поля нульової характеристики з неархімедовим нормуванням. Сформульовано достатні умови для єдиності та існування розв'язку. Наведено явну формулу для єдиного розв'язку, яка має вигляд суми ряду, що сходиться за неархімедовою нормою.

Різницеве рівняння відповідає нескінченній системі лінійних рівнянь. Доведено, що у випадку, коли неявне різницеве рівняння має єдиний розв'язок, його можна знайти, використовуючи правило Крамера. Також у статті наведені деякі результати, що полегшують пошук розв'язку неявного різницевого рівняння над кільцем поліномів.

Ключові слова: різницеве рівняння; неархімедове нормування; кільце поліномів.

\section{Implicit linear difference equations over a non-Archimedean ring \\ A. B. Goncharuk \\ V. N. Karazin Kharkiv National university \\ 4 Svobody sqr., Kharkiv, 61022, Ukraine}

Over any field an implicit linear difference equation one can reduce to the usual explicit one, which has infinitely many solutions - one for each initial value. It is interesting to consider an implicit difference equation over any ring, because the case of implicit equation over a ring is a significantly different from the case of explicit one. The previous results on the difference equations over rings mostly concern to the ring of integers and to the low order equations. In the present article the high order implicit difference equations over some other classes of rings, particularly, ring of polynomials, are studied.

To study the difference equation over the ring of integer the idea of considering $p$-adic integers - the completion of the ring of integers with respect to the non-Archimedean $p$-adic valuation was useful. To find a solution of such an equation over the ring of polynomials it is naturally to consider the same construction for this ring: the ring of formal power series is a completion of the ring of polynomials with respect to a nonArchimedean valuation.

The ring of formal power series and the ring of $p$-adic integers both are the particular cases of the valuation rings with respect to the non-Archimedean valuations of some fields: field of Laurent series and field of $p$-adic rational numbers respectively. In this article the implicit linear difference equation over a valuation ring of an arbitrary field with the characteristic zero and non-Archimedean valuation are studied. The sufficient conditions for the uniqueness and existence of a solution are formulated. The explicit formula for the unique solution is given, it has a form of sum of the series, converging with respect to the non-Archimedean valuation. 
Difference equation corresponds to an infinite system of linear equations. It is proved that in a case the implicit difference equation has a unique solution, it can be found using Cramer rules. Also in the article some results facilitating the finding the polynomial solution of the equation are given.

Keywords: difference equations; non-Archimedean valuation; ring of polynomials.

Article history: Received: 23 December 2020; Final form: 10 June 2021;

Accepted: 13 June 2021. 